\title{
Development of Action Robot for NHK Robot Contest of "College of Technology"*
}

\author{
Taku Miura**, Masato Kashiwagi**, Ryuusuke Watanabe**, and Kiichi Yoshida** \\ ** Dept. of Robotics, Tokyo Metropolitan College of Industrial Technology \\ 8-17-1, Minami-senju Arakawa-ku Tokyo Japan 116-0003
}

\begin{abstract}
In NHK Robot Contest of "College of Technology"(this is called Kosen Robocon for short), students of College of Technology contend with robot manufactured by themselves. It is thought in general that winning the championship is the best result in Contest. By contrast, there are some teams for robots action performance, the author's team is latter one. The team is named "mIui", and there are manual robot called "miu-kun" with stilts and automatic robot called "i-chan" with Bamboomerang and Jacob's Ladder. The purpose of this paper is to introduce the robots, were developed for appealing interest of manufacturing. In several demonstrations, "mIui" present revolution orbit was interested by people of all ages, thereby usefulness of appealing robot results are confirmed.
\end{abstract}

Key words: Robocon, College of Technology, Two-legged robot, Stilts, Banboomerang

\section{Introduction}

In 2009, the robots were manufactured by students of College of Technology, as shown in Figure 1. The robots named "mIui" because the authors do not require winning in competition of Kosen Robocon, and were developed for appealing interest of manufacturing. Therefore team name decide "mIui" which show "wIn!" with flip vertical. The robot as shown in Figure 1(a) is "miu-kun" seem riding Stilts, and (b) is "i-chan" with Bamboomerang and Jacob's Ladder. This paper is to introduce Two-legged mechanism, Bamboomerang Shooting method and motion of boomerang cap.

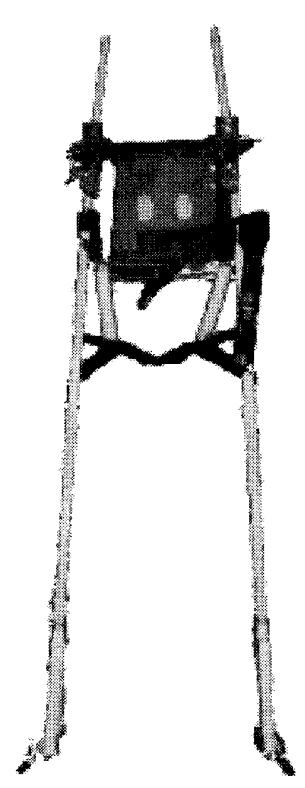

(a)

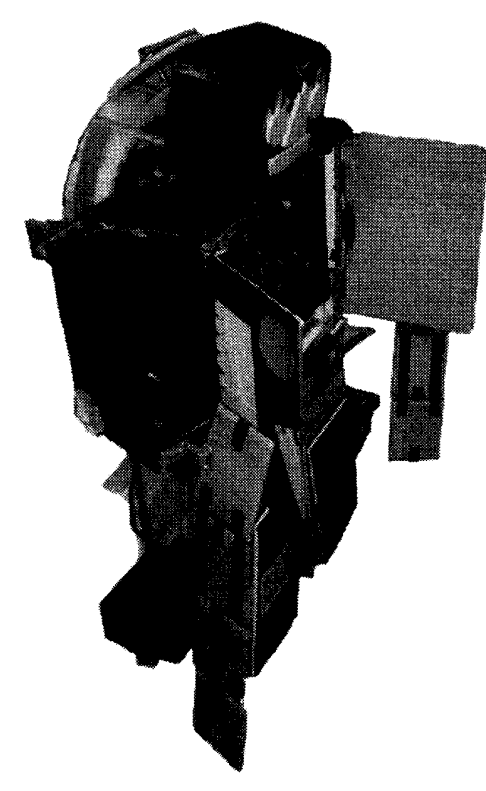

(b)

Figure 1 "miu-kun" and "i-chan" robot. 


\section{Rule of Kosen Robocon 2009}

In 2009 theme of Kosen Robocon is "DANCIN' COUPLE", couple of two robots contend other one with point score from dancing performance. First, manual robot is put in Start Zone, and automatic robot is put in Couple Zone. Started competition, if robots perform the task, score 10 points. There are 8 types of task,

(1) "Present": Manual robot presents original objects to automatic robot.

(2) "Pair Dance": Couple must dance for 10 or more second.

(3) "Pole Turn": Couple goes to the circuit of Present Pole.

(4) "Syncronized Spin": Couple rotates on themselves 5 or more times,.

(5) "Lift": The robot lifts up other one with 5 or more times walks.

(6) "Rolling Jump", the robot jumps, and rotates on itself in air. (30 bonus points.)

(7) "Star Stage": Couple climbs onto Star Stage.

(8) "Star Couple": Couple puts original objects on Star Pole.

Higher score team within 3 minutes is winner.

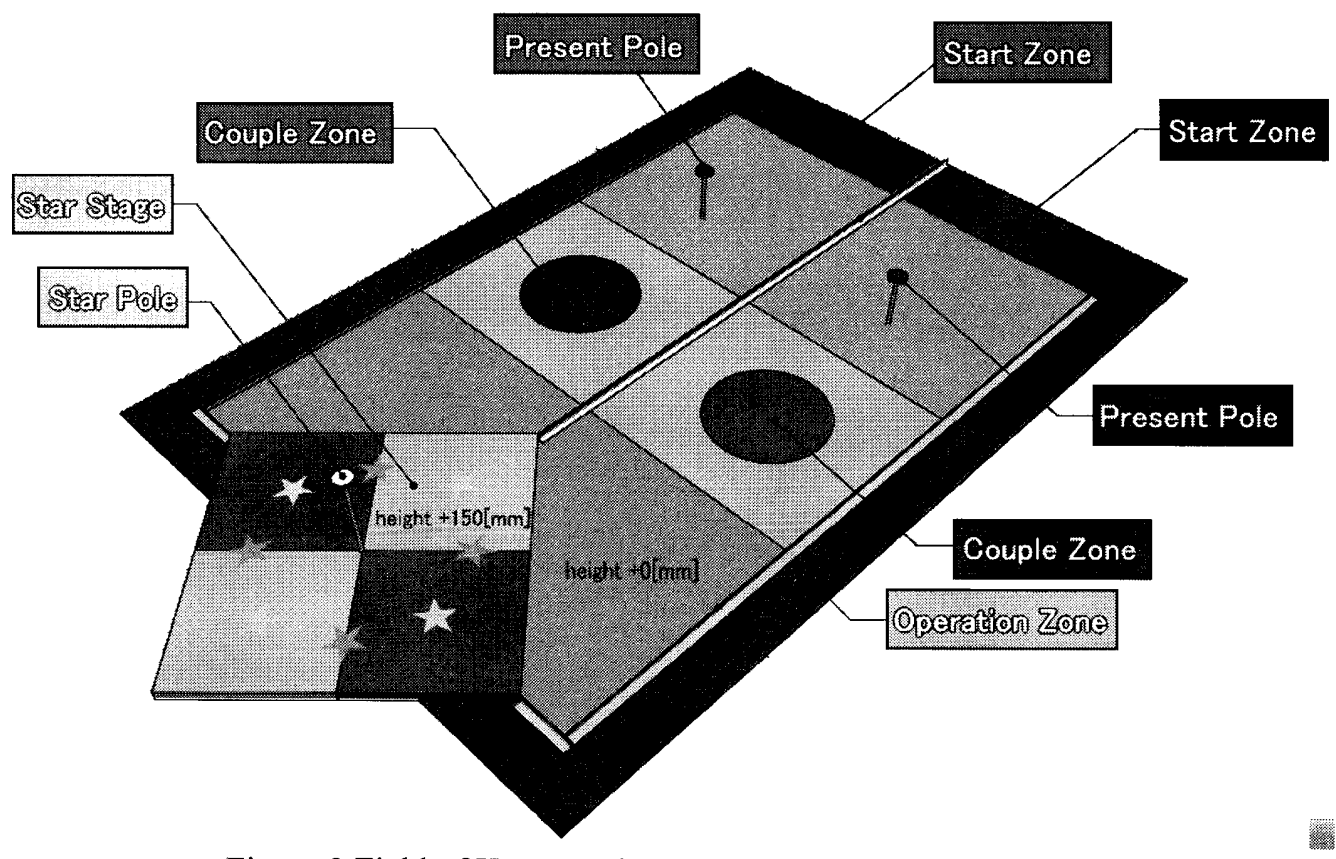

Figure 2 Field of Kosen Robocon 2009, "DANCIN' COUPLE".

\section{3. "miu-kun" with stilts}

The robot with Stilts which is two-leg of two points were researched by authors. However successful example with walking were not found. Therefore "miu-kun" can stand and walk by 2 lines. As shown in Figure 3, "miu-kun" is a model of two-legged mechanism with 3 degree of freedom.

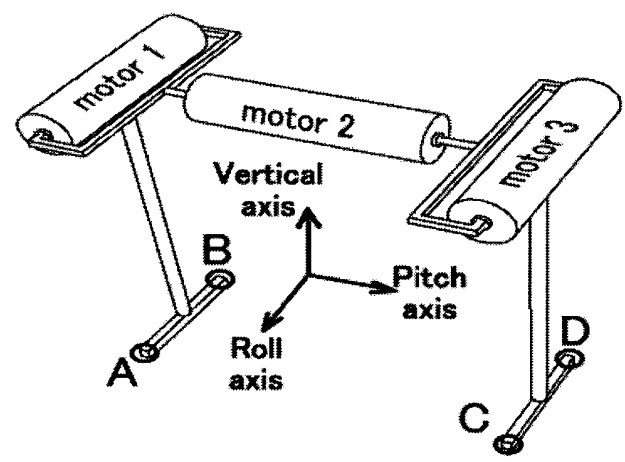

Figure 3 Model of Two-legged Mechanism. 


\section{Control of "miu-kun"}

DC servomotor with reasonable compact size and high output were not found by the authors. PID (Proportional-Integral-Derivative) angle control motor which is produced by themselves was assembled with DC geared motor and potentiometer as shown in Figure 4.

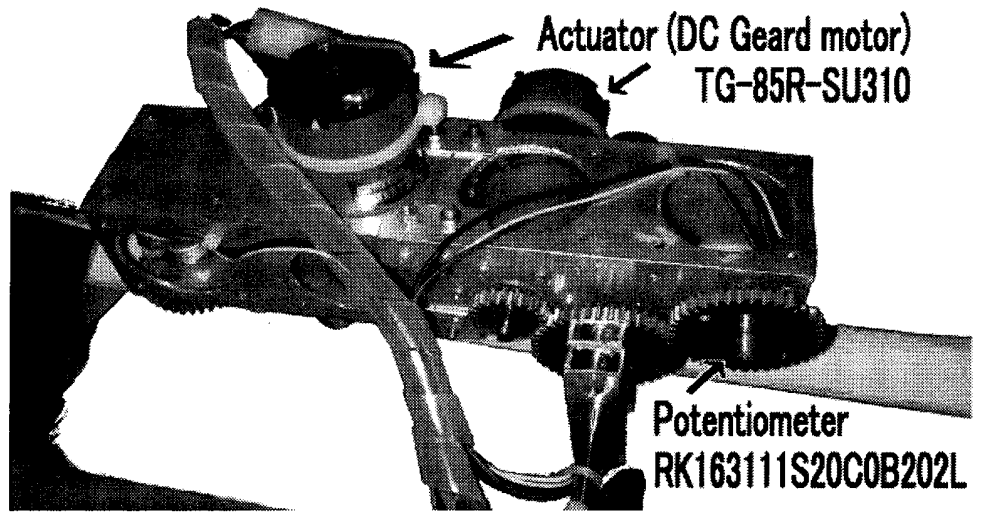

Figure 4 DC Servo motor.

For easy care for PID angle control, modular hardware was manufactured with DC geared motor, the potentiometer and aluminum box. Table 1 shows specification for "miu-kun" and necessary parts for making the module.

Table $1 \mathrm{Spec}$ for "miu-kun" (Two-legged Mechanism)

\begin{tabular}{|l|l|l|}
\hline \multicolumn{1}{|c|}{ Parts } & \multicolumn{1}{c|}{ Model number } & \multicolumn{1}{c|}{ Product company } \\
\hline Microcomputer & PIC16F887, PIC16F88 & Microchip \\
\hline Potentiometer & RK163111S20C0B202L & ALPS ELECTRIC \\
\hline Actuator(motor) & TG-85R-SU310 & TSUKASAELECTRIC \\
\hline FET & SUP85N15-21 & Vishay Siliconix \\
\hline Power & Lithium Polymer & $(11.1[\mathrm{~V}], 2800[\mathrm{mAh}])$ \\
\hline
\end{tabular}

\section{Two-legged mechanism of "miu-kun"}

In stable environment, basic answer is two-legged mechanism without gyroscope for attitude control. Therefore, "mlui" employs patterned walking by sequential logic control. Figure 5 (1) to (5) shows aspect of patterned walking.

(1) Starting from stable environment.

(2) C and D are lifted up with revolution of Motor1.

(3) Back to original angle of Motor1, thereby A, B and D support the robot.

(4) Because of A and D on the ground, "mIui" kinks around A and D.

(5) Because of B and C on the ground "mIui" can walk one time from start.

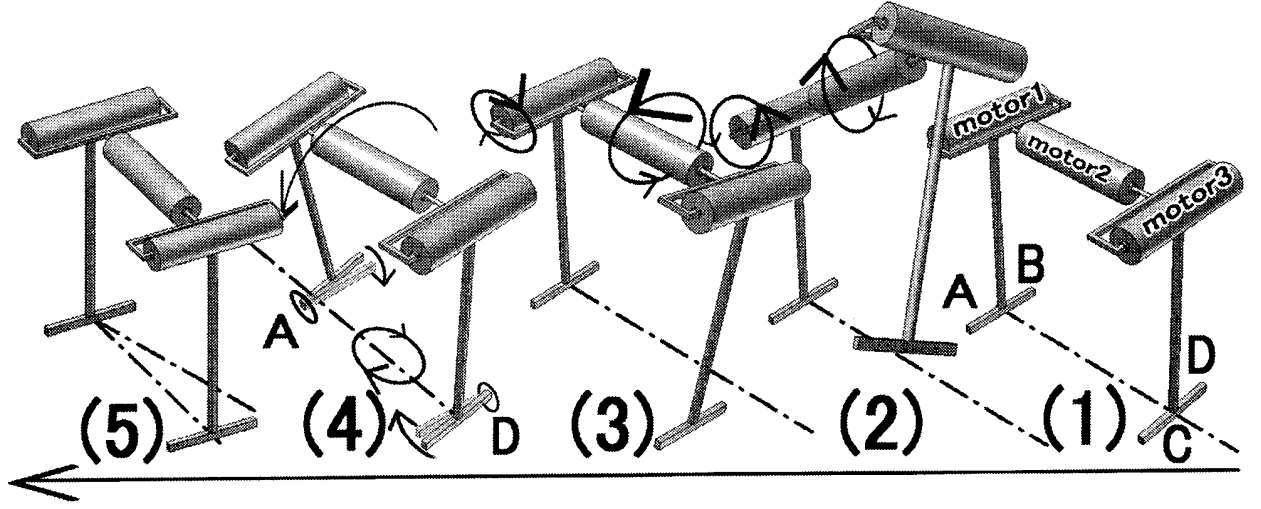

Figure 5 Working on Model of two-legged mechanism. 


\section{Development of Automatic Robot "i-chan"}

The author's College opens a lot of manufacturing workshops for primary schoolchildren. Returnable toys have very good reputation fot children.

The robot with playing returnable toys appeals to fun of the manufacturing.

\subsection{Bamboomerang}

Bamboomerang is the bamboo-copter which returns to themselves after taking off. Their performed orbit is analysed by the author's laboratory.

Figure 6 is bamboomerang. Bamboomerang has weight on blade and silicon sand on stick. Weight and silicon sand hold high-speed turn.

Figure 7(a) is result of bamboomerang's orbit analysis, and Figure 7(b) is real orbit.
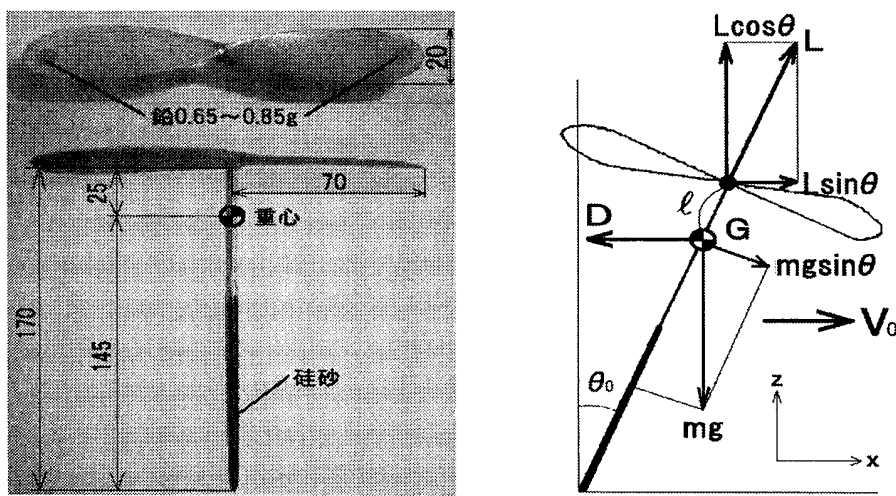

Figure 6 Bamboomerang and Coordinate axis.

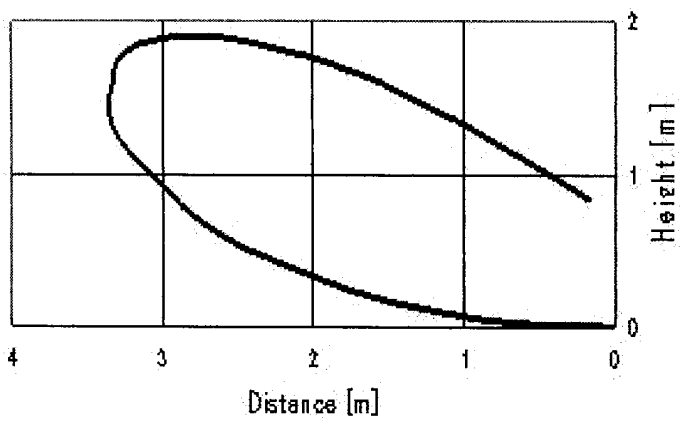

(a)

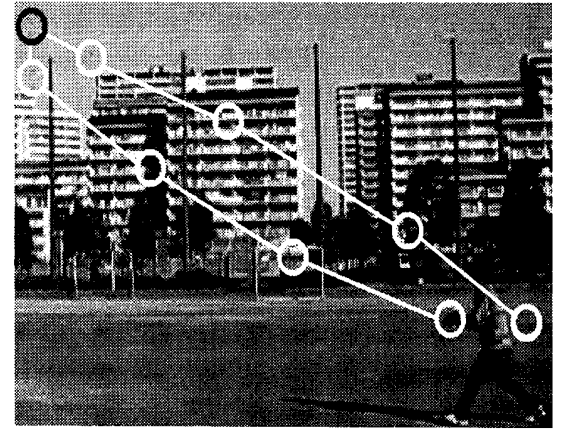

(b)

Figure 7 Analytical locus and Real locus.

\subsection{Launcher of bamboomerang}

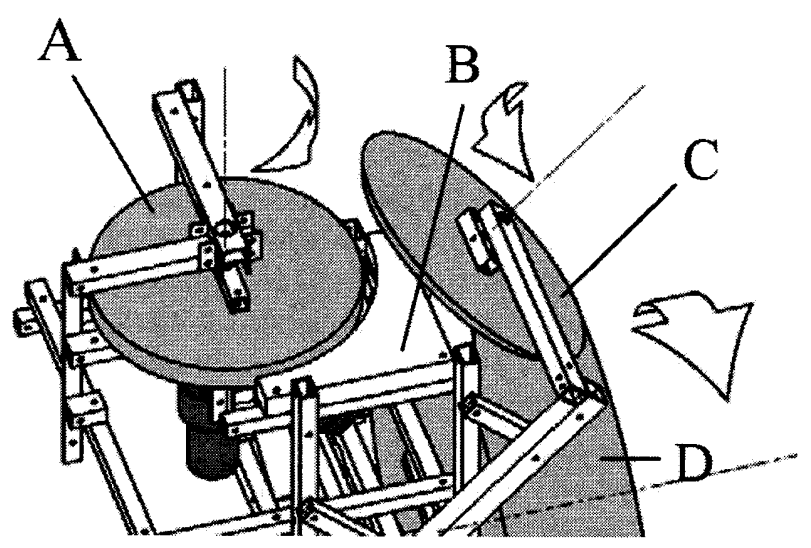

Figure 8 Bamboomerang launcher. 
Figure 8 is Launcher of bamboomerang. The sticks of bamboomerangs are sandwiched between a disk "A" and guide "B". Due to rotating the disk, bamboomerang moves with turning. The movement of bamboomerang is the same as the planetary-gear's it.

Disk " $A$ " and bamboomerang's movement is the same as a spur gear. Guide " $B$ " and bamboomerang's movement is the same as an internal gear. The following expressions are consisting from these. Then the real value and the calculation result are as follows.

\begin{tabular}{|ll|}
\hline Disk "A" Direct & $: \mathrm{D}=150 \mathrm{~mm}$ \\
Rev. & $: \mathrm{N}=330 \mathrm{rpm}$ \\
Disk "C" Rev. & $: \quad 32 \mathrm{rpm}$ \\
Disk "D" Rev. & $: \quad 1.3 \mathrm{rpm}$ \\
Bamboomerang stick Direct & $: \mathrm{d}=7.5 \mathrm{~mm}$ \\
\hline
\end{tabular}

$$
\begin{aligned}
& n=\frac{D}{d} N=\frac{150}{7.5} \times 330=6600[\mathrm{rpm}] \\
& v=\frac{1}{2} \pi D N=\frac{\pi}{2} \times 150 \times \frac{330}{60} \approx 1300[\mathrm{~mm} / \mathrm{s}]
\end{aligned}
$$

" $C$ " in Figure 8 is double disk which cut the cone. " $D$ " in Figure 8 is a disk which holds 12 bamboomerangs which is attached by Velcros. These arrive with one which was attached to bamboomerang newly. Bamboomerang is installed in the edge of Velcro of the disk " $D$ ".

Figure 9 is a state of transferring bamboomerang from disk " $D$ " to disk "C".
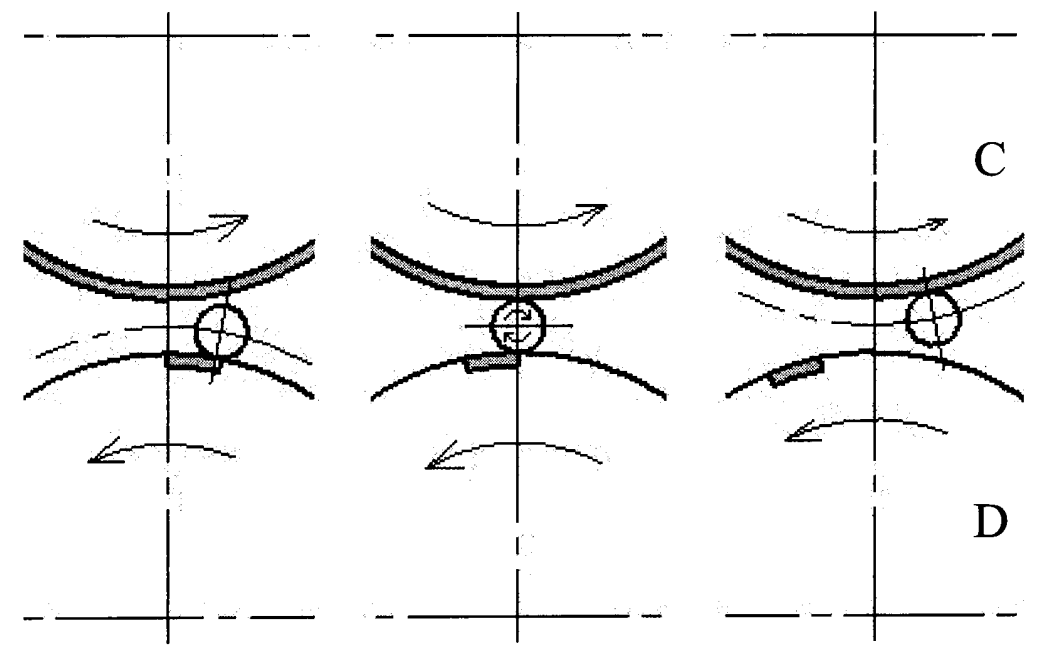

Figure 9 Transfer Bamboomerang.

When bamboomerang which is installed on a disk " $D$ " touches the disk " $C$ ", it turns. Bamboomerang turned sticks to disk "C" apart from disk "D".

When a disk turns like Figure 9, bamboomerang is fired. Because it cannot arrange disk " $\mathrm{D}$ " to the side that disk "C" inclines.

\subsection{Boomerang paper cup}

Boomerang paper cup orbit is analysed by the author's laboratory too. Connect the bottom of the paper cup together are connected by tape as shown in Figure 10(a). Three rubber bands are connected. It is wrapped the joint with two laps. And the left rubber band is thinned in right above. The paper cup returns by Magnus effect as shown in Figure 10(b) when it is separated while drawing an elliptic orbit. 


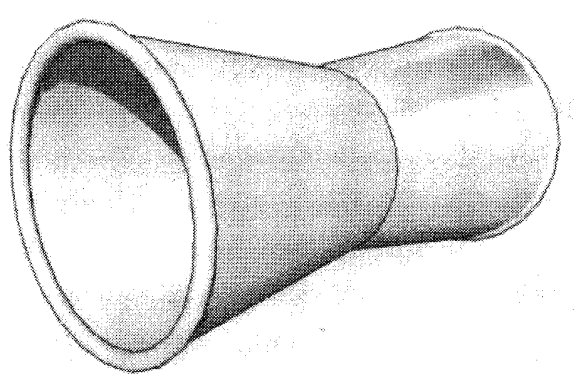

(a)

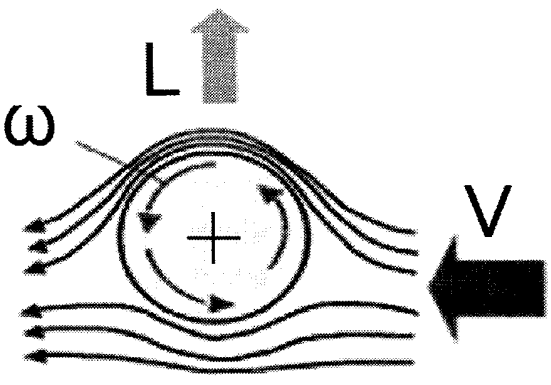

(b)

Figure 10 Boomerang paper cup and Magnus effect.

Figure 11 is forces acting on a paper cup. The exercise equation is made from now on. Figure 12(a) is the result that analyzed orbit by Runge-kutta method from an expression. And Figure 12(b) is real orbit.

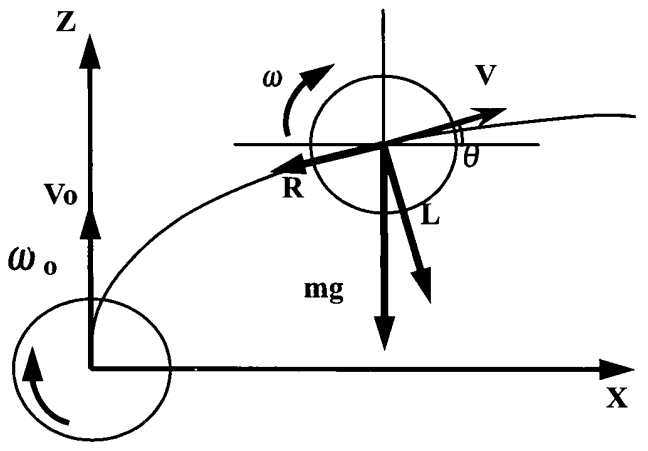

Figure 11 Coordinate axis.

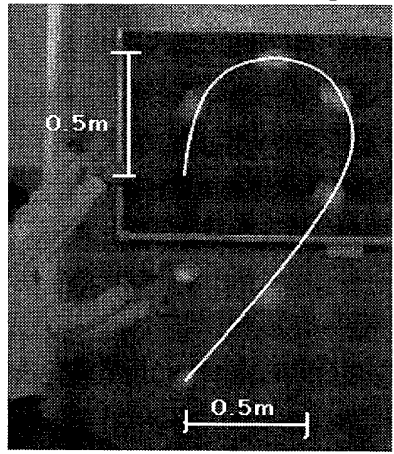

(a)

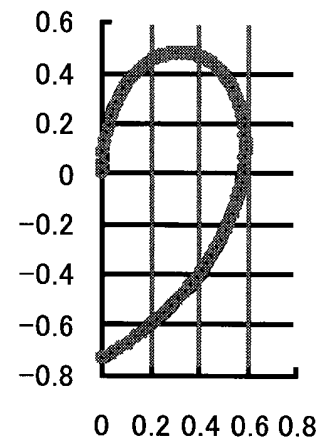

(b)

Figure 12 Analytical locus and Real locus.

\section{References}

1) Homepage of "NHK Robot Contest of "College of Technology"”, http://www.official-robocon.com/jp/kosen/index.html

2) I. SHIMOYAMA et al: "Dynamical Walk of Stilts Type Biped Locomotion", The Japan Society of Mechanical Engineers

3) K.Yoshida et al: "Analyses of Loci of Bamboomerangs and Their Educational Effects", 1st WIETE Annual Conference on Engineering and Technology Education Pattaya, Thailand, 22-25 February 2010

4) R.Watanabe et al: "Manufacturing and Analyses of Boomerang paper cup", The Japan Society of Mechanical Engineers 2010 annual conference, in Japanese

Nagoya, Japan, 5-9 September 2010 